\title{
Number and Density of AMPA Receptors in Single Synapses in Immature Cerebellum
}

\author{
Jun-ichi Tanaka, ${ }^{1,2}$ Masanori Matsuzaki, ${ }^{1,3}$ Etsuko Tarusawa, ${ }^{1,2}$ Akiko Momiyama, ${ }^{2}$ Elek Molnar, ${ }^{5}$ Haruo Kasai, ${ }^{1,3}$ and \\ Ryuichi Shigemoto ${ }^{1,2,4}$ \\ ${ }^{1}$ Department of Physiological Sciences, Graduate University for Advanced Studies, Sokendai 444-8787, Japan, Divisions of ${ }^{2}$ Cerebral Structure and ${ }^{3}$ Cell \\ Physiology, National Institute for Physiological Sciences, Myodaiji, Okazaki 444-8787, Japan, ${ }^{4}$ Core Research for Evolutional Science and Technology, Japan \\ Science and Technology Corporation, Kawaguchi, Saitama 332-0012, Japan, and ${ }^{5}$ Medical Research Council Centre for Synaptic Plasticity, Department of \\ Anatomy, School of Medical Sciences, University of Bristol, Bristol BS8 1TD, United Kingdom
}

The number of ionotropic receptors in synapses is an essential factor for determining the efficacy of fast transmission. We estimated the number of functional AMPA receptors at single postsynaptic sites by a combination of two-photon uncaging of glutamate and the nonstationary fluctuation analysis in immature rat Purkinje cells (PCs), which receive a single type of excitatory input from climbing fibers. Areas of postsynaptic membrane specialization at the recorded synapses were measured by reconstruction of serial ultrathin sections. The number of functional AMPA receptors was proportional to the synaptic area with a density of $\sim 1280$ receptors/ $\mu \mathrm{m}^{2}$. Moreover, highly sensitive freeze-fracture replica labeling revealed a homogeneous density of immunogold particles for AMPA receptors in synaptic sites $\left(910 \pm 36\right.$ particles $\left./ \mu \mathrm{m}^{2}\right)$ and much lower density in extrasynaptic sites $\left(19 \pm 2\right.$ particles/ $\left.\mu \mathrm{m}^{2}\right)$ in the immature PCs. Our results indicate that in this developing synapse, the efficacy of transmission is determined by the synaptic area.

Key words: AMPA; cerebellum; freeze fracture; postnatal; Purkinje cell; receptor; slice; synapse; ultrastructure; glutamate

\section{Introduction}

In the CNS, the transmission of information is mainly performed at chemically mediated synapses composed of the presynaptic terminal, synaptic cleft, and postsynaptic membrane. Each component has influence on the efficacy of synaptic transmission via several mechanisms at the level of single synapses (Franks et al., 2003; Liu, 2003). Nevertheless, the mechanism of synaptic transmission has been typically studied by investigating electrical responses from many thousands of synapses (i.e., population responses), because neurons are normally connected by multiple synaptic contacts. It remains unclear to what extent the properties of individual synapses could be deduced from the population responses. Differences in synaptic efficacies, properties, and types of receptors expressed at individual synapses have been revealed recently by electrophysiological (Auger and Marty, 1997; Dobrunz and Stevens, 1997; Nusser et al., 2001) and optical (Matsuzaki et al., 2004) methods. Therefore, it is essential to investigate synaptic functions in single synapses.

Dynamic regulation of the receptor number is primarily re-

Received 0ct. 13, 2004; revised Nov. 30, 2004; accepted Dec. 2, 2004.

This work was supported by Core Research for Evolutional Science and Technology from the Japan Science and Technology Corporation and by Ministry of Education, Culture, Sports, Science and Technology of Japan Grant 15082210. J.-i.T. was supported by the Sasakawa Scientific Research Grant from the Japan Science Society. We are grateful to Kazuhiko Nakadate for advice in electron microscopical technique and discussion, Yugo Fukazawa for helpful comments about SDS-digested freeze-fracture replica labeling results, and Jun Noguchi for purification of 4-methoxy-7-nitroindolinyl-caged L-glutamate.

Correspondence should be addressed to Dr. Ryuichi Shigemoto, Division of Cerebral Structure, National Institute for Physiological Sciences, Myodaiji, 0kazaki 444-8787, Japan. E-mail: shigemot@nips.ac.jp.

DOI:10.1523/JNEUROSCI.4256-04.2005

Copyright $\odot 2005$ Society for Neuroscience $\quad$ 0270-6474/05/250799-09\$15.00/0 sponsible for expression of long-term synaptic plasticity (Linden, 2001; Lei et al., 2003). It is also suggested that differences in the number of postsynaptic receptors contribute to the spatial scaling of excitatory inputs depending on the location of synapses in hippocampal pyramidal cells (Smith et al., 2003). Visualization of postsynaptic structures would help us to investigate morphological properties involved in such regulation of the receptor number. For example, a positive correlation was revealed between mean amplitude of miniature glycinergic currents and mean size of gephyrin clusters in neurons of the anteroventral cochlear nucleus (Lim et al., 1999). In the hippocampus, currents from larger and mushroom-type spines were larger than those from smaller and thin spines (Matsuzaki et al., 2001; Smith et al., 2003), and the number of immunogold particles for AMPA receptors was approximately proportional to the area of postsynaptic density (Nusser et al., 1998; Takumi et al., 1999). However, until now, the relationship between the number of functional receptors and the synaptic area at individual synapses has not been revealed in the same preparation.

Matsuzaki et al. (2001) have established a two-photon uncaging technique of 4-methoxy-7-nitroindolinyl-caged L-glutamate (MNI-glutamate) applicable at the level of single synapses. This method enables us to examine electrophysiological characteristics of AMPA receptors, which have a primary importance in fast excitatory synaptic transmission in the CNS, with precisely identified locations of stimulation in the recorded cells. In the present study, we combined the two-photon uncaging method and electron microscopic measurements of the recorded synapses in postnatal day 3-4 (P3-P4) rat Purkinje cells (PCs). We thus directly investigated the relationship between the receptor number 
and the synaptic area and estimated the density of functional AMPA receptors in single synapses. Moreover, a highly sensitive immunogold labeling method, SDS-digested freeze-fracture replica labeling (SDS-FRL) (Fujimoto, 1995; Pereda et al., 2003), was used to reveal two-dimensional and quantitative distribution of AMPA receptors. This method allowed us to investigate variability of AMPA receptor density in single synapses. Our results indicate that the number of AMPA receptors is scaled to the size of synapses in P3-P4 PCs.

\section{Materials and Methods}

Slice preparation and electrophysiological recording. Parasagittal cerebellar slices (300 $\mu \mathrm{m}$ thickness) were prepared from P3-P4 Sprague Dawley rats as described previously (Momiyama et al., 2003) in accordance with the animal experiment committee of the National Institute for Physiological Sciences (Okazaki, Japan). The cold slicing solution contained (in mM) $125 \mathrm{NaCl}, 2.5 \mathrm{KCl}, 1 \mathrm{CaCl}_{2}, 5 \mathrm{MgCl}_{2}, 26 \mathrm{NaHCO}_{3}, 1.25 \mathrm{NaH}_{2} \mathrm{PO}_{4}$, and 25 D-glucose, bubbled with $95 \% \mathrm{O}_{2} / 5 \% \mathrm{CO}_{2}$ gas. For electrophysiological recording, $\mathrm{CaCl}_{2}$ was raised to $2 \mathrm{~mm}$ and $\mathrm{MgCl}_{2}$ was decreased to $1 \mathrm{~mm}$. PCs were identified from their location and morphology using an upright microscope (BX50WI; Olympus, Tokyo, Japan) equipped with a water immersion objective lens (LUMPlanFL $60 \times$ water/infrared; numerical aperture, 0.9 ). Whole-cell recording was made at $-70 \mathrm{mV}$ using an Axopatch 200B amplifier (Axon Instruments, Foster City, CA) from PCs within lobules $8-10$ at room temperature $\left(22-25^{\circ} \mathrm{C}\right)$, in the presence of D-2-amino-5-phosphonopentanoic acid (D-AP-5) (50 $\mu \mathrm{M}$; NMDA receptor antagonist), 7-(hydroxyimino)cyclopropa[b]chromen-1acarboxylate ethyl ester (CPCCOEt) (100 $\mu \mathrm{M}$; metabotropic glutamate receptor type 1 antagonist) (Litschig et al., 1999), bicuculline methiodide (10 $\mu \mathrm{M} ; \mathrm{GABA}_{\mathrm{A}}$ receptor antagonist), strychnine hydrochloride (1 $\mu \mathrm{M}$; glycine receptor antagonist), tetrodotoxin (TTX) $(1 \mu \mathrm{M})$, and cyclothiazide (CTZ) (50 $\mu \mathrm{M}$; AMPA receptor desensitization inhibitor) (Partin et al., 1996). The pipette solution contained (in mM) $140 \mathrm{CsCl}, 2 \mathrm{NaCl}, 10$ HEPES, 10 EGTA, $2 \mathrm{Mg}_{2}$ ATP, 0.5 GTP, 2 D-ascorbic acid, and 0.5 calcein, adjusted to $\mathrm{pH} 7.3$ with $\mathrm{CsOH}$. Series resistance $\left(R_{\mathrm{s}}\right)$ and cell capacitance $\left(C_{\mathrm{m}}\right)$ were monitored by applying positive voltage steps $(5 \mathrm{mV}, 30 \mathrm{~ms})$ and were not compensated during recording. The currents were filtered at $5 \mathrm{kHz}$ and sampled at $20 \mathrm{kHz}$.

D-AP-5, 1,2,3,4-tetrahydro-6-nitro-2, 3-dioxo-benzo[f] quinoxaline7-sulfonamide (NBQX), 6-cyano-7-nitroquinoxaline (CNQX), CPCCOEt, and CTZ were purchased from Tocris Cookson (Bristol, UK), bicuculline methiodide and strychnine hydrochloride were purchased from Sigma (St. Louis, MO), and TTX was purchased from Alomone Labs (Jerusalem, Israel). MNI-glutamate was synthesized and purified as described previously (Matsuzaki et al., 2001).

Methods for two-photon uncaging of MNI-glutamate were similar to those described previously (Matsuzaki et al., 2001), unless stated otherwise. Fluorescence images of recorded cells were captured by using a mode-locked femtosecond-pulse Ti:sapphire laser (Tsunami; Spectra Physics, Mountain View, CA) attached to a laser-scanning microscope (Fluoview; Olympus). Non-crowded dendritic segments running as parallel as possible to the focal plane were selected. MNI-glutamate (12 mM) applied locally via a glass pipette was uncaged at $720 \mathrm{~nm}$ with the incident power of 5.1-6.8 $\mathrm{mW}$ for $1 \mathrm{~ms}$ per pixel for pseudorandom mapping (at an interval of $100 \mathrm{~ms}$ ) and $2 \mathrm{~ms}$ for nonstationary fluctuation analysis (NSFA) (at an interval of 5-10 s). These power and irradiation times were selected for sufficient concentration of glutamate and stable recordings with minimum photo damage. The laser was gated by a mechanical shutter (Uniblitz, Rochester, NY) controlled by a custom-made software based on LabView (National Instruments, Austin, TX). The point spread function of the focal volume of two-photon excitation was estimated as $0.39 \mu \mathrm{m}$ [full-width at half-maximal (FWHM)] laterally and $1.28 \mu \mathrm{m}$ axially, as described previously (Matsuzaki et al., 2001).

NSFA. In the present study, to estimate precisely the properties of AMPA receptors in single synapses, we set the following criteria: (1) sufficient isolation of hot spots ( $\geq 2.3 \mu \mathrm{m}$ from neighboring hot spots; see Results); (2) $>0.29 \mathrm{kHz}$ for a cutoff frequency of filtering by $R_{\mathrm{s}}$ and $C_{\mathrm{m}}$ (RC filtering); and (3) the time stability of 2pEPSC amplitudes
(Spearman's rank-order correlation test; $p>0.05$ ). Data were rejected when any of these criteria was unsatisfied.

2 pEPSCs were evoked every $5-10 \mathrm{~s}$, filtered at $2 \mathrm{kHz}$ and sampled at 10 $\mathrm{kHz}$, and then analyzed to yield their peak amplitude, 10-90\% rise time and $62 \%$ decay time. After testing the stability of peak amplitudes using the Spearman's rank-order correlation test, the decay phases of 2pEPSCs from peak to $40-100 \mathrm{~ms}$ of $10-26$ traces were analyzed to estimate a single channel conductance, the number, and an open probability of functional AMPA receptors by using NSFA (Sigworth, 1980). Variance associated with the decay phase of current responses was plotted against amplitude of the mean current, and the current-variance relationship was fitted with the following equation:

$$
\sigma^{2}=i I-\frac{I^{2}}{N}+\sigma_{b}^{2}
$$

where $I$ is a mean current, $i$ is a single channel current, $N$ is the number of functional channels, and $\sigma_{b}^{2}$ is a background noise variance. The theoretical curve was constrained to the background noise variance, estimated from pre-baseline of each trace $(10 \mathrm{~ms})$. The conductance value $(\gamma)$ was calculated from the fitted value for $I$ and the measured reversal potential. Peak open probability $\left(P_{\mathrm{o}}\right.$, peak $)$ was estimated by dividing the average peak amplitude by $i N\left(V_{\text {hold }}-V_{\text {rev }}\right)$.

Ultrastructural analysis of recorded synapses. Recorded slices were fixed with $4 \%$ paraformaldehyde (PFA) (TAAB, Berks, UK) and 0.05\% glutaraldehyde (GA) (Nacalai, Kyoto, Japan) in $100 \mathrm{~mm}$ phosphate buffer, $\mathrm{pH}$ 7.4, for $30 \mathrm{~min}$ at $4^{\circ} \mathrm{C}$, followed by $4 \%$ PFA and $0.05 \%$ GA in $100 \mathrm{~mm}$ cacodylate buffer $(\mathrm{CB}), \mathrm{pH} 7.4$, overnight at $4^{\circ} \mathrm{C}$. After washing in $\mathrm{CB}$, the slices were then transferred into 3,3'-diaminobenzidine (DAB) solution $(0.2 \mathrm{mg} / \mathrm{ml}$ in Tris-HCl, $\mathrm{pH} 8.0)$, and the recorded cells were identified with an inverted microscope (IX70; Olympus) equipped with a modelocked laser (Tsunami; Spectra Physics) with the laser power of 15-20 $\mathrm{mW}$ at $800 \mathrm{~nm}$.

To identify recorded cells and synapses quickly and accurately under light and electron microscopes, we established a photoconversion method with two-photon excitation, taking advantages of its outstanding spatial resolution ( $2 \mathrm{p}$ photoconversion method). The usual photoconversion method (Lübke, 1993) uses radicals from fluorophores injected into cells by irradiation of excitation light. In contrast, this 2 p photoconversion method uses radicals from not only fluorophores but also endogenous radical generators, probably NADPH and/or flavoprotein, which have two-photon absorption cross sections at 720-800 nm (Xu et al., 1996; Huang et al., 2002) (see Results). This method could thus mark arbitrary areas ( $\sim 1 \mu \mathrm{m}$ dots or lines) (see Fig. 3$)$ in tissues with DAB end products within several minutes. The two-photon laser at $800 \mathrm{~nm}$ was irradiated for $2-4 \mathrm{~s}$ for dots and for $1-2 \mathrm{~min}$ for lines in the DAB solution, $\mathrm{pH}$ 8.0. After the $2 \mathrm{p}$ photoconversion, slices were postfixed with $2 \%$ osmium tetroxide for $30 \mathrm{~min}$ at $4^{\circ} \mathrm{C}$. After washing, slices were stained with $1 \%$ uranyl acetate and dehydrated with graded ethanol and propylene oxide, then embedded in Durcupan resin (Fluka, Bucks, Switzerland).

Serial ultrathin sections ( $70 \mathrm{~nm}$ thickness) were cut from regions with the DAB marking by $2 p$ photoconversion as an indicator for recorded cells. Recorded cells and/or dendrites were examined with an electron microscope (JEOL1200; JEOL, Tokyo, Japan) and photographed at a magnification of $10,000-12,000 \times$ for three-dimensional reconstructions of dendrites and 20,000-30,000 $\times$ for measurements of synaptic areas. The stimulated synapse(s) was identified from the reconstructed dendrites by using Reconstruct (http://synapses.mcg.edu/), and the synaptic area was measured as described previously (Momiyama et al., 2003). The density of functional AMPA receptors was calculated by dividing the number of functional AMPA receptors by the postsynaptic area. The distance between centers of $2 p$-evoked synapses and the nearest synapses was measured in reconstructed dendritic profiles projected to the XY plane.

SDS-FRL method. Slices (200 $\mu \mathrm{m}$ thickness) were prepared according to the method described above for electrophysiological recording. The slices were then cryoprotected in the following cold solution (in mM): 250 sucrose, $2.5 \mathrm{KCl}, 1 \mathrm{CaCl}_{2}, 5 \mathrm{MgCl}_{2}, 26 \mathrm{NaHCO}_{3}, 1.25 \mathrm{NaH}_{2} \mathrm{PO}_{4}$, and 25 
D-glucose, bubbled with $95 \% \mathrm{O}_{2} / 5 \% \mathrm{CO}_{2}$ gas. The slices were frozen quickly by a high-pressure freezing machine (HPM 010; Bal-Tec, Balzers, Liechtenstein). The frozen slices were then freeze-fractured and replicated with carbon $(10 \mathrm{~nm})$, shadowed by platinum $(2 \mathrm{~nm})$, and then replicated with carbon (10 nm) again in BAF 060 (Bal-Tec). After thawing, tissue debris attached to the replicas were digested with gentle stirring at $30^{\circ} \mathrm{C}$ overnight in the following solution: $15 \mathrm{~mm}$ Tris[hydroxymethyl] aminomethane, $20 \%$ sucrose, and $2.5 \%$ sodium lauryl sulfate. The replicas were then washed in PBS and reacted with a pan-AMPA receptor (GluR1-4) antibody (1 $\mu \mathrm{g} / \mathrm{ml})$ (Nusser et al., 1998) at $4^{\circ} \mathrm{C}$ overnight twice, followed by incubation in an anti-rabbit IgG coupled to $5 \mathrm{~nm}$ gold particle (British Biocell International, Cardiff, UK) for $1 \mathrm{~h}$ at $37^{\circ} \mathrm{C}$. Specificity of this antibody was extensively characterized previously (Nusser et al., 1998). When the primary antibody was omitted or replaced with $1 \%$ normal rabbit serum, no selective labeling was observed. To examine shrinkage of synapses by fixation (see Results), we also used replica samples made from animals perfused transcardially with $4 \%$ PFA according to the method described above.

The replicas were examined with an electron microscope (JEOL1010) and photographed at a magnification of 50,000-60,000 $\times$. Immunogold particles were counted in excitatory postsynaptic areas indicated by clusters of intramembrane particles (IMP cluster) (Harris and Landis, 1986) and extrasynaptic sites around the IMP clusters on the exoplasmic fracture-face (E-face) of PC dendrites. Measurement was performed in two animals, and results were pooled because the density for immunogold particles on IMP clusters was not significantly different. Immunogold particles on the protoplasmic fracture-face (P-face) of PC dendrites were defined as background labeling. The length of synapse and/or dendritic segments on electron micrographs was calibrated by using a calibration grid (Ted Pella, Redding, CA). The outline of synaptic sites was demarcated freehand, and the area of synaptic and extrasynaptic sites was measured by Scion Image (Scion Corporation, Frederick, MD). For extrasynaptic AMPA receptors on the E-face of PCs, the distance between each immunogold particle and the closest center of IMP cluster was measured, and the particles were allocated into 200-nm-wide bins.

Simulation. To investigate influences of neighboring synapses on the estimation of synaptic properties and validity of estimation by NSFA, we used Monte Carlo techniques. All of the Monte Carlo simulations were performed using ChanneLab software (Synaptsoft, Decatur, GA) with the AMPA receptor model constructed by Häusser and Roth (1997). Time constants into all desensitized states were zeroed to mimic the present experimental conditions in the presence of CTZ (Dzubay and Jahr, 1999). The concentration profile of uncaged glutamate at any distance from the center of photolysis was generated by the equation in the report by Matsuzaki et al. (2001) using Mathematica 4.1 (Wolfram Research, Champaign, IL) with a concentration of MNI-glutamate at 9.6 $\mathrm{mm}$ [assuming that the dilution rate was $80 \%$ (Dittman and Regehr, 1997)], an incident power of two-photon laser at $6.8 \mathrm{~mW}$, and $2 \mathrm{~ms}$ irradiation. The diffusion constant of glutamate $(D)$ was set at $0.1 \mu \mathrm{m}^{2} /$ ms, unless stated otherwise. The other parameters were in accordance with Matsuzaki et al. (2001). Current traces (50 ms long/trace) were generated with a sampling rate of $10 \mathrm{kHz}$, a $\gamma$ of $10 \mathrm{pS}$, a $N$ of 100 , and a driving force of $-70 \mathrm{mV}$. A Gaussian noise of $2 \mathrm{pA}$ SDs, which corresponded to the baseline noise of the recorded 2pEPSCs, was added to the simulated postsynaptic currents (PSCs), unless stated otherwise. In simulation, 100 PSCs were generated for each condition.

Errors on parameter estimations in the conventional NSFA elicited by the RC filtering were also evaluated with the experimentally estimated $R_{\mathrm{s}}$ and $C_{\mathrm{m}}$ values as described previously (Momiyama et al., 2003), and then the parameters experimentally estimated were compensated for the errors.

Statistical analysis was done by Prism (GraphPad Software, San Diego, CA) and Statistica (StatSoft, Tulsa, OK). Data were represented by mean $\pm \operatorname{SEM}(n=$ number of synapses or cells), unless stated otherwise. Unless stated otherwise, distribution and mean values between groups were compared by the Kolmogorov-Smirnov (K-S) test and Bonferroni's multiple $t$ test, respectively, with a confidence level of 0.05 . Correlation was examined by using Spearman's rank-order correlation test.

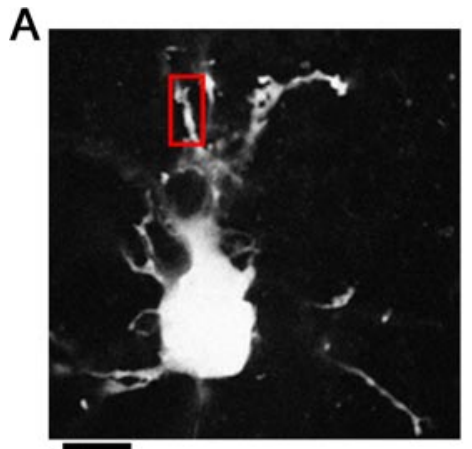

$$
10 \mu \mathrm{m}
$$

E

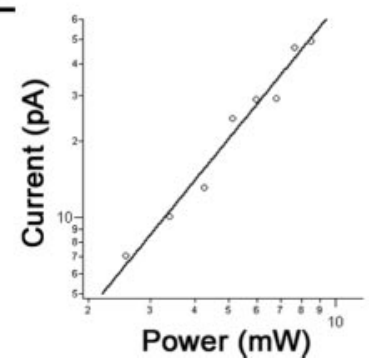

B

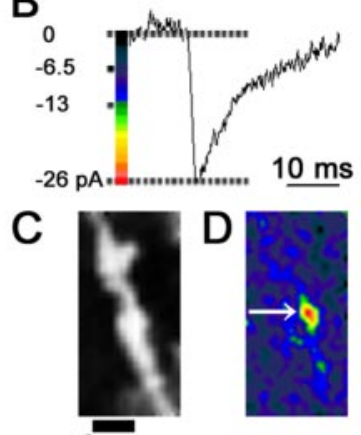

$2 \mu \mathrm{m}$

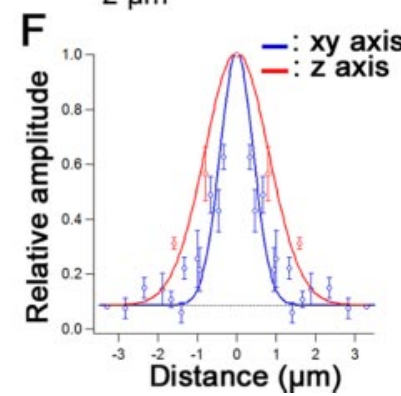

Figure 1. Hot spot of glutamate sensitivity and spatial resolution of two-photon uncaging. $A$, Fluorescence (calcein) image of a recorded $P C$ in the $P 3$ rat cerebellum. A red frame indicates a region of interest (ROI) for glutamate sensitivity mapping shown in ( and $D$. $B$, Representative trace of 2 pEPSCs obtained during repetitive photolysis ( $6.8 \mathrm{~mW}, 1 \mathrm{~ms} /$ pixel). C, A magnified fluorescence image in the ROI. D, A glutamate sensitivity map of the $2 \mathrm{pEPSC}$ amplitudes represented by pseudocolor coding. $E$, Double-logarithmic plot of the dependence of $2 p E P S C$ amplitudes on the incident power. No current was evoked by light alone (data not shown). F, Relative amplitude of 2pEPSCs evoked by irradiation for $2 \mathrm{~ms}$ at $6.8 \mathrm{~mW}$ along the $x y$ (blue) and $z$ (red) axes. Amplitudes of 2pEPSCs were normalized by the amplitude evoked at the center of the hot spot. The smooth lines represent Gaussian curves fitted to experimental data, and the fitted curves were constrained to 1.5 times the SD of baseline variance $(-3 \mathrm{pA})$. The FWHM is $1.2 \mu \mathrm{m}$ on the horizontal axis and $2.3 \mu \mathrm{m}$ on the vertical axis. The dotted line represents the threshold of detection ( $-3 \mathrm{pA})$. Error bars represent SEM.

\section{Results}

\section{"Hot spot" of glutamate sensitivity and spatial resolution of} 2pEPSCs in P3-P4 PCs

$\mathrm{PCs}$ in $\mathrm{P} 3-\mathrm{P} 4$ rat cerebellum have a restricted arborization of dendrites (Fig. $1 A$ ) and sparsely located synapses made by climbing fibers (CFs) as the only type of excitatory input (Altman and Bayer, 1997). At the electron microscopic level, we confirmed that synapses were sparsely distributed on PC dendrites but often made by boutons with closely located multiple active zones in proximal dendrites (data not shown). Therefore, to investigate isolated single synapses, we chose middle segments of the dendrites for the uncaging experiments.

Whole-cell recordings were made from visually identified PCs in slices, and dendrites were irradiated with two-photon laser at $720 \mathrm{~nm}$ wavelength for $1 \mathrm{~ms}$ with puffing of MNI-glutamate in the presence of D-AP-5, CPCCOEt, bicuculline, strychnine, TTX, and CTZ. EPSC-like currents were elicited (Fig. $1 B$ ) by the twophoton uncaging (2pEPSCs) from clustered regions indicating hot spots of high glutamate sensitivity on the dendrites (Fig. $1 D$, arrow). The 2 pEPSCs elicited at these hot spots were completely blocked by a low dose of NBQX $(1 \mu \mathrm{M})$, which preferentially blocks AMPA receptors, or CNQX (10 $\mu \mathrm{M}$; data not shown). The reversal potential $\left(V_{\text {rev }}\right)$ of 2 pEPSCs was $-6.1 \mathrm{mV}$, on average $(n=5$ synapses in 5 cells). These results indicate that the $2 \mathrm{pEP}-$ SCs are mediated by activation of AMPA receptors. The amplitude of 2pEPSCs showed a supralinear dependence (power expo- 
Table 1. Slower kinetics of 2 EESSCs rather than mEPSCs is partially caused by activation of AMPA receptors in neighboring synapses

\begin{tabular}{|c|c|c|c|c|c|c|c|}
\hline \multirow[b]{3}{*}{ Shutter duration } & \multicolumn{6}{|l|}{$2 \mathrm{pEPSCs}$} & \multirow[b]{3}{*}{ mEPSCs } \\
\hline & \multicolumn{2}{|l|}{ Total } & \multicolumn{2}{|l|}{ Hot spot distance $>2.3 \mu \mathrm{m}$} & \multicolumn{2}{|c|}{ Hot spot distance $<2.3 \mu \mathrm{m}$} & \\
\hline & $1 \mathrm{~ms}$ & $2 \mathrm{~ms}$ & $1 \mathrm{~ms}$ & $2 \mathrm{~ms}$ & $1 \mathrm{~ms}$ & $2 \mathrm{~ms}$ & \\
\hline $10-90 \%$ rise (ms) & $3.03 \pm 0.19(n=76)$ & $3.88 \pm 0.36(n=22)$ & $2.81 \pm 0.26^{* *}(n=36)$ & $3.20 \pm 0.36^{* *}(n=13)$ & $3.22 \pm 0.26(n=40)$ & $4.86 \pm 0.58^{*}(n=9)$ & $0.72 \pm 0.06 \mathrm{~ms}(n=107)$ \\
\hline $62 \%$ decay (ms) & $20.4 \pm 1.2(n=70)$ & $25.4 \pm 4.7(n=22)$ & $15.7 \pm 1.3^{* *}(n=36)$ & $19.1 \pm 1.5^{* *}(n=13)$ & $25.3 \pm 1.7^{* *}(n=34)$ & $34.5 \pm 10.8(n=9)$ & $4.0 \pm 0.6 \mathrm{~ms}(n=106)$ \\
\hline
\end{tabular}

The kinetics of $2 \mathrm{pEPSCs}$ from hot spots isolated $>2.3 \mu \mathrm{m}$ was significantly faster than that from total hot spots but still had slower kinetics than that of mEPSCs. Some values for hot spots isolated $<2.3 \mu \mathrm{m}$ were significantly slower than those for total hot spots. Values were not corrected for RC filtering and are expressed as mean \pm SEM. The number of hot spots for $2 p E P S C s$ and the number of events for mEPSCs are indicated in parentheses. ${ }^{*} p<0.05 ;{ }^{* *} p<0.01$ (Bonferroni's multiple $t$ test).

nent, $2.3 \pm 0.2 ; n=5$ ) (Fig. $1 E$ ) on the incident power as predicted by the two-photon excitation and the cooperativity of glutamate binding to AMPA receptors (Matsuzaki et al., 2001). The spatial resolution of 2pEPSCs was inferred from isolated hot spots obtained by irradiation for $2 \mathrm{~ms}$, yielding the lateral and axial FWHM diameter of 1.2 and $2.3 \mu \mathrm{m}$, respectively $(n=3)$ (Fig. $1 F)$. The 2 pEPSCs went back to the threshold $(-3 \mathrm{pA})$ of detection at 2.3 and $3.0 \mu \mathrm{m}$ from center of the hot spot in the horizontal and vertical axis, respectively (Fig. $1 F$ ).

\section{Influence of neighboring hot spots on the 2pEPSC kinetics}

The 2pEPSCs in P3-P4 PCs had strikingly slower kinetics compared with that of miniature EPSCs (mEPSCs) in the same cells (Table 1). It has been reported that several mechanisms such as spillover (Carter and Regehr, 2000; Barbour, 2001; DiGregorio et al., 2002) or pooling of glutamate (Barbour et al., 1994; Otis et al., 1996) could cause slowing of synaptic currents. As described above, glutamate uncaged by two-photon excitation could diffuse and activate receptors in a region within a radius of $\sim 2.3$ $\mu \mathrm{m}$. This distance obviously overwhelms distances at which spillover would be caused in several central synapses $[0.436 \mu \mathrm{m}$ in the CA1 hippocampal synapses (Rusakov and Kullmann, 1998), 0.77 $\mu \mathrm{m}$ in mossy fiber-granule cell (MF-GC) synapses (DiGregorio et al., 2002)]. To avoid an interaction between neighboring hot spots, we excluded hot spots closer than $2.3 \mu \mathrm{m}$ to each other. Actually, we found no significant correlation between the $62 \%$ decay time and the distance between these isolated $(>2.3 \mu \mathrm{m})$ hot spots (data not shown). Furthermore, mean values of the $10-90 \%$ rise time and the $62 \%$ decay time became significantly faster after the exclusion of closely located hot spots (Table 1). Nevertheless, the kinetics was still slower than that of mEPSCs. This is partly because of neighboring synapses not visible as hot spots as shown later and probably because of concentration profiles of uncaged glutamate as well as pooling of glutamate (see Discussion).

\section{Estimation of the electrophysiological properties and density of AMPA receptors in single synapses}

At the center of well-isolated hot spots, 2pEPSCs were evoked 50-60 times (Fig. 2A,B). The mean amplitude of 2pEPSCs was $-45.9 \pm 4.6 \mathrm{pA}(n=22)$, which was larger than that of mEPSCs $(-21.1 \pm 0.8 \mathrm{pA} ; n=107)$. We then analyzed 2 pEPSCs by NSFA (Sigworth, 1980). The mean current from multiple trials was plotted against variance associated with the decay phase from the peak (Fig. 2 B) and fitted with the theoretical equation (see Materials and Methods). The single channel conductance $(\gamma)$ was $11.4 \pm 1.0 \mathrm{pS}$ [6.4-18.2 pS; coefficient of variation (CV), 0.31; $n=13$ hot spots from 12 cells], the number of functional AMPA receptors $(N)$ was $109 \pm 16(32-264 ; \mathrm{CV}, 0.53 ; n=13)$, and the $P_{\text {o, peak }}$ was $0.62 \pm 0.04(0.35-0.86 ; \mathrm{CV}, 0.23 ; n=13)$.

By using a photoconversion with a two-photon laser (see Materials and Methods), we could identify 11 recorded cells (of the
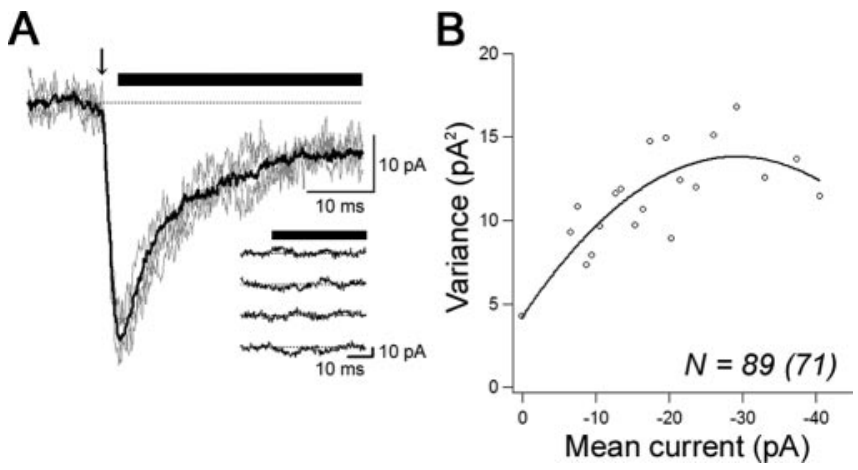

Figure 2. Estimation of properties of AMPA receptors in a single synapse. $A$, Superimposed representative four 2pEPSCs traces (gray) and an averaged trace (black) analyzed with NSFA at the hot spot shown in Figure 1. The arrow indicates a timing of photolysis (6.8 mW, $2 \mathrm{~ms}$ ), and the horizontal bars indicate the time window used for NSFA. Inset, Representative currents after subtraction of the average current. $B$, Variance of $2 \mathrm{pEPSC}$ plotted versus the mean amplitudes. Data were fitted by parabolic theoretical functions (see Materials and Methods). Raw variance points were binned at $1 \mathrm{pA}$.

13 cells analyzed by NSFA) with electron microscopy (Figs. 3, 4). We measured the area of the recorded synapse (Fig. 3) as well as the distance from the nearest neighboring synapse (Fig. 4). In 4 of 11 hot spots, synapses stimulated by the two-photon uncaging were separated $>2.3 \mu \mathrm{m}$ from the nearest synapses (Figs. 3, $4 A-D$, single synapse). The density of AMPA receptors was $1420 \pm 170$ receptors $/ \mu \mathrm{m}^{2}(n=4)$. In 7 of 11 hot spots, the nearest neighboring synapses existed within $2.3 \mu \mathrm{m}$ along the dendrites (Fig. $4 E-H$, multiple synapses). Except two synapses located within $0.5 \mu \mathrm{m}$, these neighboring synapses were not detected as hot spots, probably because of their location in a different $z$-axis from the photolysis plane or too small responses. In the present study, we set $-3 \mathrm{pA}$ as a threshold of detection for $2 \mathrm{pEP}$ SCs, corresponding to $46.9 \mathrm{pS}$ [holding potential $\left(V_{\text {hold }}\right)=-70$ $\mathrm{mV}$; reversal potential $\left.\left(V_{\text {rev }}\right)=-6.1 \mathrm{mV}\right]$. With this condition, synapses with $<16$ AMPA receptors $\left(\gamma\right.$ and $P_{\text {o, peak }}$ are assumed to be 8.0 and 0.36 , respectively; both values are calculated from experimental estimation in the present study) cannot be detected. In addition, in 3 of 11 hot spots ( 1 with a single synapse and 2 with multiple synapses), an invagination of postsynaptic membrane was observed (data not shown). The invagination was rare for nonstimulated synapses in recorded cells and in nonrecorded cells $(\sim 2 \%)$ and might be caused by a morphological change associated with plasticity (Carroll et al., 2001) or photo damage (Koester et al., 1999; Hopt and Neher, 2001; Kiskin et al., 2002). We thus excluded the invaginated synapses from additional analysis. After correction for filtering effects induced by series resistance and cell capacitance (RC filtering; see Materials and Methods), the mean density of functional AMPA receptors in single synapses was $1280 \pm 80$ receptors $/ \mu \mathrm{m}^{2}(n=3)$ (Table 2$)$. 
A

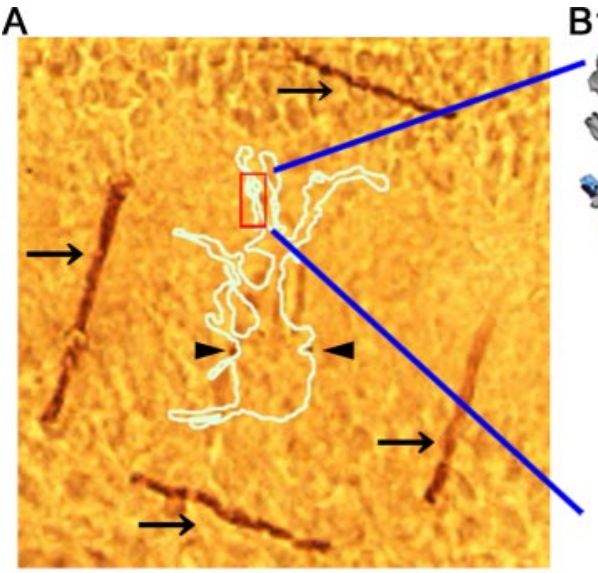
B1 B2

C

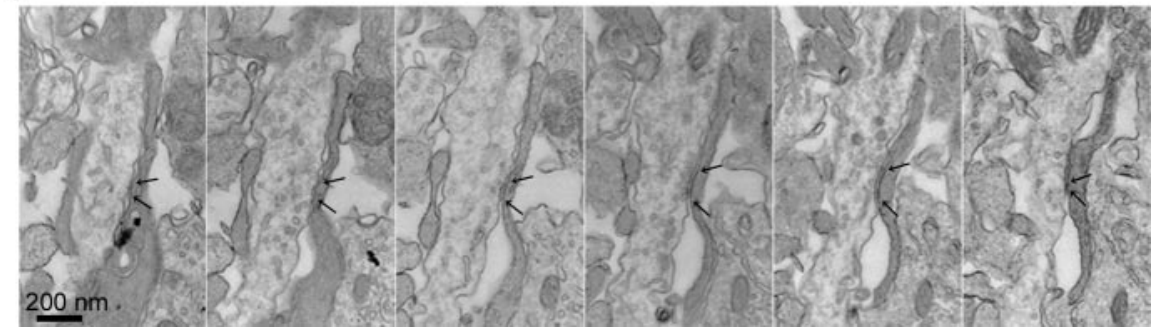

Figure 3. Identification and measurement of the postsynaptic area of synapses analyzed by NSFA. $A$, The image of embedded fixed slices with marking by $2 p$ photoconversion. Dark brown lines (arrows) and dots (arrowheads) are oxidized end products of DAB. The white outline indicates the recorded cell. $B$, Three-dimensional reconstruction of the mapped dendrite. Shown at left and right is the dendrite (gray) with and without (Fs (blue), respectively. Red areas are synaptic areas. The synapse stimulated by uncaged glutamate is shown in the inset. C, Serial electron micrographs of the synapse corresponding to the hot spot shown in Figure 1. Arrows indicate the edges of the synaptic sites.

In Table 3 , kinetics of 2pEPSCs, properties of AMPA receptors estimated with NSFA, and ultrastructural characterization are summarized for hot spots with single and multiple synapses. In case of hot spots with multiple synapses, the kinetics tended to be slower and the single channel conductances were larger than those for single synapses, being consistent with our simulation (Fig. 5).

\section{Estimation of the number and density of immunogold particles for AMPA receptors by SDS-FRL}

SDS-FRL can reveal a two-dimensional structure of cell membranes and distribution of membrane proteins (Fujimoto, 1995; Pereda et al., 2003). Excitatory synaptic areas are indicated by IMP clusters on the E-face (Harris and Landis, 1986). In the present study, we used SDS-FRL for P3 rat unfixed cerebellar slices prepared similarly to those for electrophysiological experiments to investigate distribution of AMPA receptors in PC dendrites (Fig. 6). The primary antibody used in the present study reacts with a common extracellular epitope of AMPA receptor subunits GluR1-4 (Nusser et al., 1998), giving immunogold labeling for AMPA receptors on the E-face. The number and density of immunogold particles in the synaptic sites were $56 \pm 45$ particles $/ \mu \mathrm{m}^{2}$ (mean $\pm \mathrm{SD}$, $10-207$ particles $\left./ \mu \mathrm{m}^{2} ; n=44\right)$ and $910 \pm$ 240 particles $/ \mu \mathrm{m}^{2}$ (mean $\pm \mathrm{SD}, 330-1460$

Neighboring synapses cause errors in the estimation by NSFA We further performed a simulation using a model of closely located synapses (Fig. 5) to systematically analyze the effect of neighboring synapses on basic properties of 2pEPSCs and estimates in NSFA. We assumed two synapses (S1 and S2) with 100 AMPA receptors $(\gamma=10 \mathrm{pS})$ having an interval of $r$ on the same $\mathrm{XY}$ plane (Fig. 5A). A photolysis was induced at $\mathrm{S} 1$ in the presence $9.6 \mathrm{~mm}$ MNI-glutamate with a $6.8 \mathrm{~mW}$ two-photon laser $(2 \mathrm{~ms}$ irradiation).

With the distance ( $r$ ) up to $0.5 \mu \mathrm{m}$, kinetics of 2 pEPSCs was apparently similar to that for a single synapse, and the amplitude of 2 pEPSCs was almost twice as that for a single synapse (Fig. $5 C$ ). With the distance $(r)$ between 0.5 and $1.5 \mu \mathrm{m}$, the rise time of 2 pEPSCs became slower than that for a single synapse, and the amplitude of 2 pEPSCs gradually decreased to that for a single synapse. With the distance $(r)$ between 1.5 and $2.5 \mu \mathrm{m}$, the decay time of 2 pEPSCs became slower than that for a single synapse, despite the result that the amplitude and rise time of 2pEPSCs were similar to those for a single synapse. When neighboring synapses existed at a distance longer than $2.5 \mu \mathrm{m}$, kinetics was similar to that for a single synapse.

Consistent with these changes in the kinetics, estimates in NSFA were reliable with the distance $(r)$ shorter than $0.5 \mu \mathrm{m}$ and longer than $2.5 \mu \mathrm{m}$ (Fig. 5D). When neighboring synapses existed at a distance from 0.5 to $2.5 \mu \mathrm{m}$, all estimates were deviated heavily from the parameters set for a single synapse, indicating that NSFA became no longer reliable. Note that the single channel conductance $(\gamma)$ was overestimated slightly (Fig. $5 D)$. particles $/ \mu \mathrm{m}^{2} ; n=44$ ), respectively. The number of immunogold particles in individual synapses was highly proportional to the size of the IMP cluster $(r=0.942)$ (Fig. 6G, red open circle), indicating a homogeneous density of AMPA receptors in this type of synapse. Labeling for extrasynaptic AMPA receptors (Fig. 6 A, arrows) was very low $\left(19 \pm 2\right.$ particles/ $\left.\mu \mathrm{m}^{2} ; n=39\right)$, and the background estimated on the P-face of PCs was extremely low $\left(0.6 \pm 0.2\right.$ particles $\left./ \mu \mathrm{m}^{2} ; n=22\right)$. The density of immunogold particles for extrasynaptic receptors decreased as distance from the center of the IMP clusters increases (Fig. 6E). In contrast with the stable labeling density in synaptic sites, labeling in extrasynaptic sites was very variable between different synapses (Fig. $6 A, C)$.

In addition, we estimated the shrinkage rate of synapses by chemical fixation of slices. We found no significant difference in the mean (Mann-Whitney's $U$ test; $p>0.05$ ) and distribution (K-S test; $p>0.05$ ) (Fig. $6 F$ ) of the synaptic areas obtained by reconstruction of immersion-fixed slices (mean \pm SD, $0.049 \pm$ $0.028 \mu \mathrm{m}^{2} ; n=60$ ), IMP cluster areas in unfixed slices (mean \pm SD, $0.059 \pm 0.041 \mu \mathrm{m}^{2} ; n=71$ ), and IMP cluster areas in perfusion-fixed animals (mean \pm SD, $0.048 \pm 0.030 \mu \mathrm{m}^{2} ; n=$ 42 ). Therefore, we did not correct the density values for shrinkage. The mean area of $2 \mathrm{p}$-evoked synapses (mean \pm SD, $0.081 \pm$ $0.049 \mu \mathrm{m}^{2} ; n=9$ ) was larger than the means of randomly selected synapses, probably because we avoided synapses with small electrophysiological responses near the detection limit $(-3 \mathrm{pA}$ corresponding to $0.016 \mu \mathrm{m}^{2}$ ). 

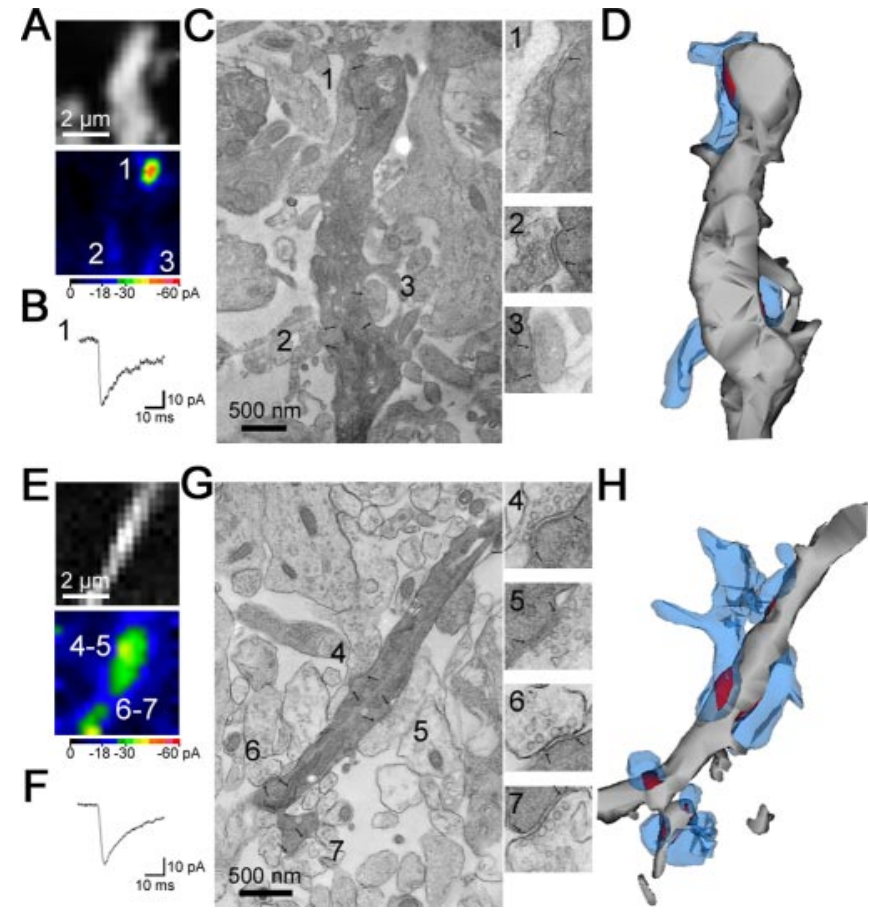

Figure 4. Measurement of distance from neighboring synapses. In some cases, each visually distinguishable hot spot corresponded to a morphologically defined single synapse distant from neighboring synapses (synapse 1 in $A--D$ ). In other cases, however, an apparent single hot spot corresponded to multiple synapses close $(<2.3 \mu \mathrm{m})$ to each other. Some of them were not visible as hot spots $(E-H)$. The fluorescence image and pseudocolor map of peak amplitudes of 2pEPSCs are shown in $A$ and E. B, F, Current traces at hot spots 1 and 4. C, G, The recorded synapses shown in $A$ and $E$ were identified and photographed under an electron microscope. The numbered hot spots in $A$ and $E$ correspond to the numbered synapses in $C$ and $G$. Inset, Electron micrographs of the synapses with higher magnification. Synaptic sites are demarcated by arrows. $D, H$, Three-dimensional images of the dendrites (gray) shown with presynaptic terminals (blue) and synaptic areas (red).

Table 2. Estimated properties of AMPA receptors in single synapses

\begin{tabular}{llll}
\hline Hot spot identification & $\mathrm{rp12}$ & $\mathrm{rp10}$ & $\mathrm{rp3}$ \\
\hline Single-channel conductance $(\mathrm{pS})$ & $7.5(10.4)$ & $6.4(9.8)$ & $10.2(15.9)$ \\
Number of AMPA receptors & $264(231)$ & $109(86)$ & $89(71)$ \\
Peak open probability & $0.59(0.52)$ & $0.42(0.37)$ & $0.71(0.62)$ \\
Synaptic area $\left(\mathrm{nm}^{2}\right)$ & 201,200 & 61,000 & 55,600 \\
Density of AMPA receptors $\left(/ \mu \mathrm{m}^{2}\right)$ & $1310(1150)$ & $1780(1410)$ & $1590(1280)$ \\
Distance from the neighboring synapse $(\mu \mathrm{m})$ & 4.42 & 2.96 & 2.66
\end{tabular}

Numbers within parentheses are values corrected for RC filtering. The distance from the nearest synapse was measured in the projected profile of each dendrite reconstructed from serial electron micrographs.

\section{Comparison of the number and density of functional AMPA} receptors and immunogold particles for AMPA receptors

After correction for the RC filtering, the number of functional AMPA receptors in single synapses was plotted against the synaptic area (Fig. 6G, blue filled circle). Although the number of functional AMPA receptors was variable $(71-231 ; n=3$; CV, 0.68$)$, it was proportional to the synaptic area, consistent with the results of SDSFRL (10-207 immunogold particles; $n=44$; CV, 0.80). Although extrasynaptic density of AMPA receptors is much lower than that of synaptic density, values for the number of functional AMPA receptors may be overestimated by contamination of extrasynaptic receptors, because uncaged glutamate can be exposed to areas larger than synaptic areas. We therefore tried to correct the density of functional synaptic AMPA receptors according to individual synaptic areas by assuming the following: (1) the density ratio of synaptic and extrasynaptic functional AMPA receptors in recorded slices was same as

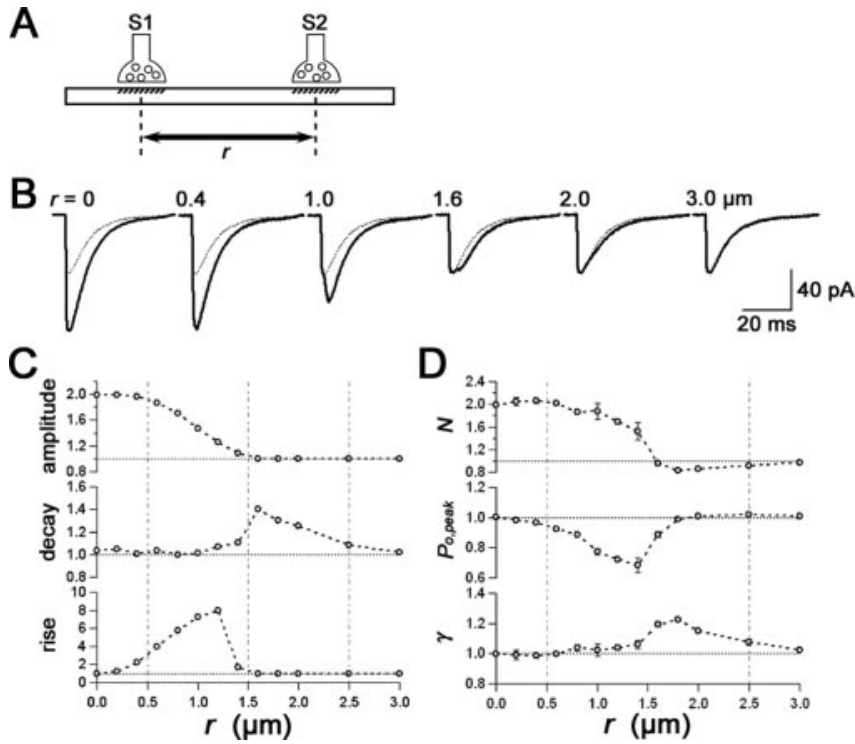

Figure 5. Simulated effects of a neighboring synapse on the 2pEPSC kinetics and the parameters estimated by NSFA. A, Synapse $\mathrm{S} 1$ is stimulated by uncaging (see Materials and Methods) in the presence of another neighboring synapse $\mathrm{S}$ located at a distance of $r$ from S1. Both S1 and S2 have 100 channels with a single-channel conductance $(\gamma)$ of $10 \mathrm{pS}$. To remove an effect of noise, a Gaussian noise was not added in this simulation. $B$, Averaged traces of simulated 2 pEPSCs in the absence (gray) and presence (black) of the neighboring synapse at various distances. Responses at $S 1$ and $S 2$ were summated linearly. C, Relative amplitude and kinetics of $2 p E P S C$ induced in the presence of the neighboring synapse at $r \mu \mathrm{m}$ from $S 1$. The rise represents a $10-90 \%$ rise time, and the decay represents a $62 \%$ decay time of simulated $2 \mathrm{pEPSCS}$. The parameters are normalized to values in the absence of $\mathbf{S 2}$ (horizontal dotted lines). The vertical dotted lines in $($ and $D$ separate regions with different effects of $S 2$ on the kinetics and estimated parameters. D, Estimated parameters by NSFA: $\gamma$, single-channel conductance; $P_{0}$, peak, peak open probability; $N$, number of functional AMPA receptors. The decay phases $40 \mathrm{~ms}$ from the apparent peak of 100 traces of summated 2pEPSCs were analyzed. The estimated parameters are normalized to values in the absence of a neighboring synapse. Data were represented by mean \pm SEM $(n=3)$. These simulations indicate that the kinetics and NSFA parameters are barely affected by neighboring synapses when they are further than $2.5 \mu \mathrm{m}$.

Table 3. Summary of the estimated properties of AMPA receptors in hot spots with single and multiple synapses

\begin{tabular}{lcc}
\hline & $\begin{array}{l}\text { Single } \\
\text { synapse }\end{array}$ & $\begin{array}{l}\text { Multiple } \\
\text { synapses }\end{array}$ \\
\hline Distance from the neighboring synapse & $r>2.3 \mu \mathrm{m}$ & $r<2.3 \mu \mathrm{m}$ \\
$10-90 \%$ rise time (ms) & $2.7 \pm 0.7$ & $3.6 \pm 0.4$ \\
$62 \%$ decay time (ms) & $15.3 \pm 3.2$ & $17.8 \pm 2.0$ \\
Single-channel conductance $(\mathrm{pS})$ & $8.0 \pm 1.1$ & $11.6 \pm 1.1$ \\
Number of AMPA receptors & $154 \pm 56$ & $90 \pm 6$ \\
Peak open probability & $0.57 \pm 0.08$ & $0.60 \pm 0.05$ \\
Density of AMPA receptors $\left(/ \mu \mathrm{m}^{2}\right)$ & $1630 \pm 190$ & - \\
Number of samples & 3 & 5
\end{tabular}

Values were not corrected for $R C$ filtering and are expressed as mean \pm SEM. The density of AMPA receptors was estimated only from single synapses.

that of immunogold labeling in and outside IMP clusters; and (2) 1 $\mu \mathrm{m}$ of radius from the center of synapses (where we detected significant density for extrasynaptic receptors) was exposed by uncaged glutamate. The ratio of contribution by extrasynaptic receptors used for the correction at each synapse was calculated to be 0.150 in rp12, 0.344 in rp10, and 0.391 in rp3 by dividing the assumed number of extrasynaptic receptors within $1 \mu \mathrm{m}$ by the number of total functional AMPA receptors (after correction for RC filtering) (Table 2). The corrected density of functional AMPA receptors in single synapses is then very homogeneous $\left(990 \pm 40\right.$ receptors $/ \mu \mathrm{m}^{2} ; n=3$; $\mathrm{CV}, 0.07$ ) (Fig. $6 \mathrm{G}$, blue open circle) and very close to the density of 


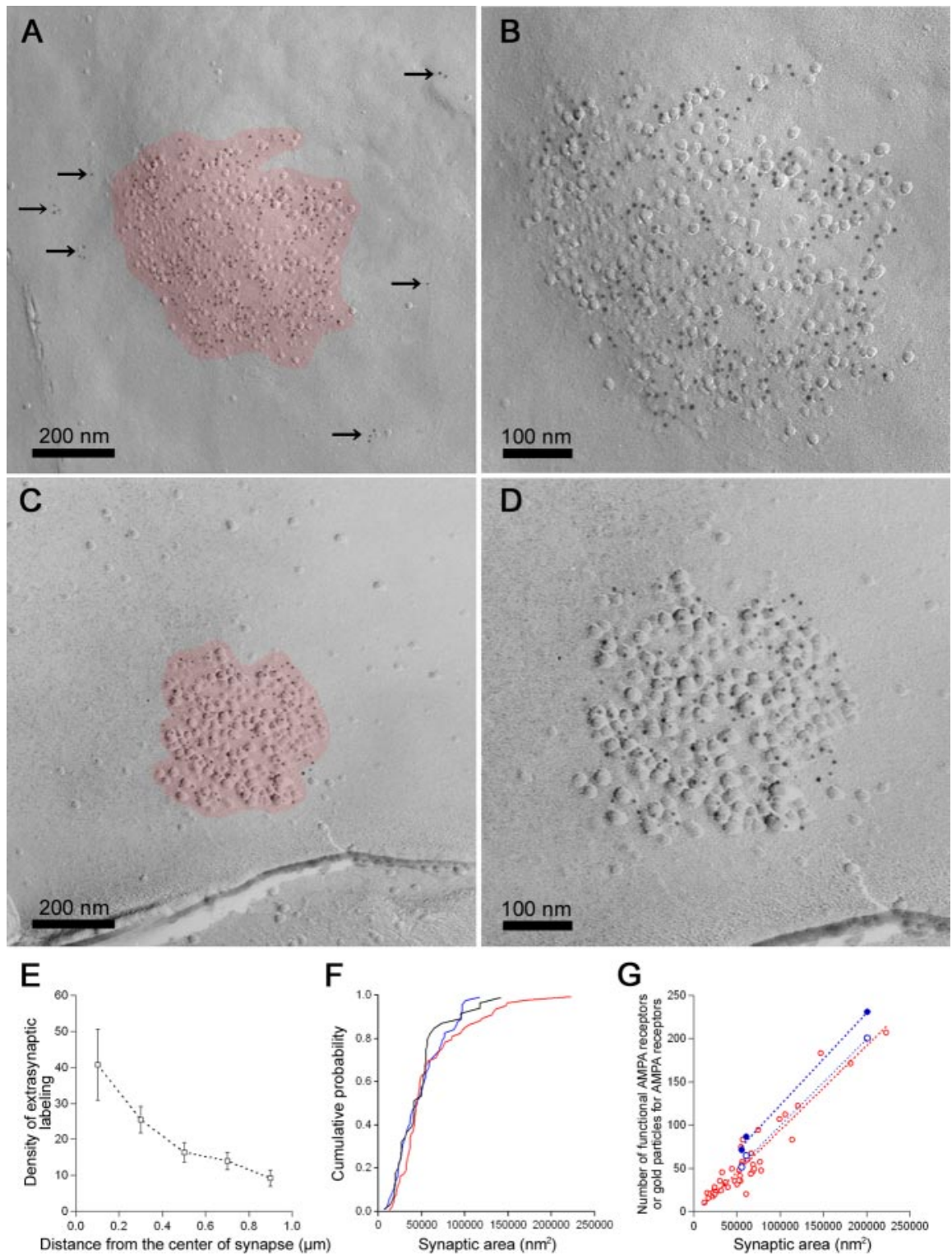

Figure 6. The number of functional AMPA receptors and immunogold particles for AMPARs are scaled to the synaptic areas. $A-D$, Representative electron micrographs of IMP clusters (red) with immunogold particles $(5 \mathrm{~nm})$ for AMPA receptors. The arrows indicate immunogold particles for extrasynaptic AMPA receptors. $B, D$, Higher-magnification electron micrographs of the IMP clusters shown in $A$ and C. $E$, The density of immunogold particles for AMPA receptor gradually decreases as distance from the center of IMP clusters increases (square). Error bars represent SEM. F, The cumulative probability plots of synaptic areas obtained from reconstructed synapses in immersion-fixed slices (blue), IMP clusters in unfixed slices (red), and perfusion-fixed animals (black). G, Linear relationship was observed between the number of functional AMPA receptors and synaptic areas (blue filled circle; $r=0.999$ ) and between the number of immunogold particles and IMP cluster areas (red open circle; $r=0.942 ;$ slope of regression line, 977.9 particles/ $\left.\mu \mathrm{m}^{2} ; n=44\right)$. The corrected density of functional AMPA receptors in single synapses for extrasynaptic AMPA receptors according to individual synaptic areas is very homogeneous ( $990 \pm 40$ receptors $/ \mu \mathrm{m}^{2} ; n=3 ; C \mathrm{CV}, 0.07$; blue open circle). Note that the number of immunogold particles for extrasynaptic AMPA receptors is variable among synapses despite the homogeneous labeling density for synaptic AMPA receptors $(A-D)$

immunogold particles. It is of note that this labeling method provides an extraordinary high labeling efficacy giving a scaling factor close to unity.

\section{Discussion}

In the present study, we directly estimated the number and density of functional AMPA receptors in single synapses by a combination of two-photon uncaging of glutamate, NSFA, and ultrastructural analysis. Moreover, comparison with results of SDS-FRL applied to unfixed slice preparations provided strong and mutually consistent ev- idence that the number of AMPA receptors is scaled to the size of the synaptic area in P3-P4 rat PCs. Because a frequency of spontaneous EPSCs is low (Momiyama et al., 2003) and multivesicular release is rare in immature PCs (Hashimoto and Kano, 2003), our results indicate that the efficacy of synaptic transmission is mainly determined by the synaptic area in P3-P4 PCs.

\section{Kinetics of 2pEPSCs in P3-P4 PCs}

The kinetics of 2 pEPSCs was slower than that of mEPSCs in the same PCs (Table 1). This finding appears different from that in cultured hippocampal neurons (Matsuzaki et al., 2001), where 2pEPSCs had a similar time course as mEPSCs. The slowing in the present study was caused, at least in part, by neighboring synapses activated by uncaged glutamate that can spread much further and wider than synaptically released glutamate $[\sim 0.7 \mu \mathrm{m}$ in theory (Otis et al., 1996)]. However, even in sufficiently isolated synapses $(\geq 2.3 \mu \mathrm{m} ; 3$ of $11)$, the $10-90 \%$ rise time $(2.7 \pm 0.7 \mathrm{~ms}$; $n=3)$ and the $62 \%$ decay time $(15.3 \pm 3.2$ $\mathrm{ms} ; n=3$ ) of 2pEPSCs elicited at $6.8 \mathrm{~mW}$ for $2 \mathrm{~ms}$ were slower than those of $\mathrm{mEP}$ SCs $(10-90 \%$ rise time; $0.71 \pm 0.1 \mathrm{~ms}$; $62 \%$ decay time; $3.0 \pm 0.7 \mathrm{~ms} ; n=13$ events) recorded in the same cells. The reason for this slowing could be a waveform of uncaged glutamate concentration and pooling of the uncaged glutamate. The continued presence of glutamate around the spine was demonstrated to slow EPSC in P11-P16 rat parallel fiber-PC synapses (Barbour et al., 1994). Actually, the kinetics of the 2pEPSCs in the present study was reproduced by simulation with a slow diffusion constant $(0.1$ $\mu \mathrm{m}^{2} / \mathrm{ms}$ ) and the concentration waveform of glutamate uncaged with 2 ms irradiation of two-photon laser (data not shown). Pooling of the released glutamate is likely to occur by, for example, some extracellular barriers hampering the diffusion of glutamate (Barbour et al., 1994), low capacity of uptake mechanism (Otis et al., 1996), and/or high-affinity binding sites (Franks et al., 2002). In addition, if the concentration or clearance rate of glutamate shows any trial-to-trial variability, this will erroneously influence the estimates of NSFA (Nusser et al., 2001). Nevertheless, we believe that our estimation by NSFA is valid because we surely removed results from synapses close to neighboring synapses within $2.3 \mu \mathrm{m}$, which make the NSFA unreliable (Fig. 5), and used the stable series of the 2pEPSC amplitudes (CV, 0.04-0.09) and kinetics over time windows for NSFA. Moreover, 2 pEPSCs obtained from single synapses had low variability in $62 \%$ decay time $(\mathrm{CV}$, 0.15 ), suggesting low variability of the clearance (Nusser et al. 2001). Actually, the reliability of NSFA was further improved 
by a slower diffusion constant of glutamate as confirmed by our simulation (data not shown), probably because of the increment of saturation level (Kruk et al., 1997).

\section{AMPA receptor density estimation in single synapses}

The density of functional receptors has been estimated by dividing the mean receptor number by the mean synaptic area in a few central synapses such as MF-GCs for AMPA receptors $(\sim 1000$ receptors $/ \mu \mathrm{m}^{2}$ ) (Silver et al., 1996). The value is close to our estimated density for AMPA receptors, indicating that a uniform receptor density across different synapses may be a general rule for ionotropic receptors in the CNS, as suggested by Nusser et al. (1997). However, such generalization may not apply for different types of synapses such as "silent" synapses proposed by several electrophysiological studies (Isaac et al., 1995). Actually, 20\% of synapses were immunonegative for AMPA receptors in hippocampal CA1 pyramidal cell spines (Nusser et al., 1998; Takumi et al., 1999). Moreover, even two different compartments of a single cell type (e.g., soma and axon initial segment of hippocampal granule cells) can have a different density of $\mathrm{GABA}_{\mathrm{A}}$ receptors (Nusser, 1999).

Momiyama et al. (2003) estimated the minimum density of AMPA receptors activated by a quantal transmitter packet to be $\sim 900$ receptors $/ \mu \mathrm{m}^{2}$ in the same preparation as we used in the present study. This value is smaller than the receptor density obtained in the present study, suggesting that AMPA receptors expressed on synaptic membranes are not saturated by a quantal transmitter packet in P3-P4 PCs, as found in P11-P17 CF-PC synapses (Wadiche and Jahr, 2001), in hippocampal neurons in cultures and acute slices (Liu et al., 1999) or calyx of Held synapses (Ishikawa et al., 2002).

We revealed the homogeneous density of AMPA receptors among synapses from P3-P4 PCs $(\mathrm{CV}=0.10$ for functional AMPA receptors and 0.26 for immunogold labeling), whereas the receptor number, which is one of the sources of quantal variability (Silver, 2003), was more variable $(\mathrm{CV}=0.68$ for functional AMPA receptors and 0.80 for immunogold particles). These results supported an idea of Momiyama et al. (2003) that the variability of quantal size should be caused by intersite variability in P3-P4 PC synapses. Similarly in GABAergic synapses, a large variability of receptor labeling number $(\mathrm{CV}, \sim 0.8)$, but with a homogeneous density $\left(\sim 1250\right.$ receptors $\left./ \mu \mathrm{m}^{2}\right)$, was found in cerebellar stellate cells by combination of psNSFA of miniature IPSCs and postembedding immunolabeling (Nusser et al., 1997). Therefore, these observations suggest a mechanism for supplying receptor contents according to synaptic areas to keep receptor density uniform.

In the present study, we dared to correct the number of functional AMPA receptors for extrasynaptic receptors. Indeed, responses against glutamate were detected by an outside-out patch from P3-P4 PC soma (Momiyama et al., 2003). In the present study, we also observed responses from extrasynaptic regions. However, they had remarkably small amplitudes and slow kinetics without clear rising and decay phases (data not shown), indicating the existence of extrasynaptic functional AMPA receptors with very low density on analyzed dendrites. This is consistent with our results by SDS-FRL (Fig. 6). However, correction of the estimated values of synaptic receptors for the extrasynaptic receptors has several potential problems. First, sensitivity of immunogold labeling for synaptic and extrasynaptic AMPA receptors may be different because of macromolecular clouding in synaptic regions (Ellis, 2001). Second, the number of extrasynaptic functional AMPA receptors may be heterogeneous among different synapses as we found for AMPA receptor labeling. Nevertheless, our estimated density after the correction showed very homogeneous density of functional AMPA receptors in single synapses (990 \pm 40 receptors $/ \mu \mathrm{m}^{2} ; n=3$; CV, 0.07$)$.

The density of immunogold particles for AMPA receptors estimated by SDS-FRL was close to that of functional AMPA receptors in the present study. The high sensitivity of SDS-FRL for AMPA receptors compared with the conventional postembedding method (Nusser et al., 1998; Takumi et al., 1999) provides us with a powerful tool to quantify the number and density of receptors in individual synapses even for small and/or distal synapses at which it is difficult to detect currents by electrophysiological methods.

Recently, several findings about heterogeneity of efficacy of synaptic transmission (Auger and Marty, 1997; Dobrunz and Stevens, 1997; Nusser et al., 2001) and modulation by synaptic activity (Matsuzaki et al., 2004) at the level of single synapses have been reported. Therefore, evaluation of parameters of identified single synapses at precisely defined locations by combination of electrophysiology and electron microscopy will be indispensable for understanding origins of difference in synaptic efficacies as well as their independent regulations within a single cell in the CNS.

\section{References}

Altman J, Bayer S (1997) Development of the cerebellar system. Boca Raton, FL: CRC.

Auger C, Marty A (1997) Heterogeneity of functional synaptic parameters among single release sites. Neuron 19:139-150.

Barbour B (2001) An evaluation of synapse independence. J Neurosci 21:7969-7984.

Barbour B, Keller BU, Llano I, Marty A (1994) Prolonged presence of glutamate during excitatory synaptic transmission to cerebellar Purkinje cells. Neuron 12:1331-1343.

Carroll RC, Beattie EC, von Zastrow M, Malenka RC (2001) Role of AMPA receptor endocytosis in synaptic plasticity. Nat Rev Neurosci 2:315-324.

Carter AG, Regehr WG (2000) Prolonged synaptic currents and glutamate spillover at the parallel fiber to stellate cell synapse. J Neurosci 20:4423-4434.

DiGregorio DA, Nusser Z, Silver RA (2002) Spillover of glutamate onto synaptic AMPA receptors enhances fast transmission at a cerebellar synapse. Neuron 35:521-533.

Dittman JS, Regehr WG (1997) Mechanism and kinetics of heterosynaptic depression at a cerebellar synapse. J Neurosci 17:9048-9059.

Dobrunz LE, Stevens CF (1997) Heterogeneity of release probability, facilitation, and depletion at central synapses. Neuron 18:995-1008.

Dzubay JA, Jahr CE (1999) The concentration of synaptically released glutamate outside of the climbing fiber-Purkinje cell synaptic cleft. J Neurosci 19:5265-5274.

Ellis RJ (2001) Macromolecular crowding: obvious but underappreciated. Trends Biochem Sci 26:597-604

Franks KM, Bartol TM, Sejnowski TJ (2002) A Monte Carlo model reveals independent signaling at central glutamatergic synapses. Biophys J 83:2333-2348.

Franks KM, Stevens CF, Sejnowski TJ (2003) Independent sources of quantal variability at single glutamatergic synapses. J Neurosci 23:3186-3195.

Fujimoto K (1995) Freeze-fracture replica electron microscopy combined with SDS digestion for cytochemical labeling of integral membrane proteins. Application to the immunogold labeling of intercellular junctional complexes. J Cell Sci 108:3443-3449.

Harris KM, Landis DM (1986) Membrane structure at synaptic junctions in area CA1 of the rat hippocampus. Neuroscience 19:857-872.

Hashimoto K, Kano M (2003) Functional differentiation of multiple climbing fiber inputs during synapse elimination in the developing cerebellum. Neuron 38:785-796.

Häusser M, Roth A (1997) Dendritic and somatic glutamate receptor channels in rat cerebellar Purkinje cells. J Physiol (Lond) 501:77-95.

Hopt A, Neher E (2001) Highly nonlinear photodamage in two-photon fluorescence microscopy. Biophys J 80:2029-2036. 
Huang S, Heikal AA, Webb WW (2002) Two-photon fluorescence spectroscopy and microscopy of $\mathrm{NAD}(\mathrm{P}) \mathrm{H}$ and flavoprotein. Biophys J 82:2811-2825.

Isaac JT, Nicoll RA, Malenka RC (1995) Evidence for silent synapses: implications for the expression of LTP. Neuron 15:427-434.

Ishikawa T, Sahara Y, Takahashi T (2002) A single packet of transmitter does not saturate postsynaptic glutamate receptors. Neuron 34:613-621.

Kiskin NI, Chillingworth R, McCray JA, Piston D, Ogden D (2002) The efficiency of two-photon photolysis of a "caged" fluorophore, $\mathrm{O}-1-(2-$ nitrophenyl)ethylpyranine, in relation to photodamage of synaptic terminals. Eur Biophys J 30:588-604.

Koester HJ, Baur D, Uhl R, Hell SW (1999) $\mathrm{Ca}^{2+}$ fluorescence imaging with pico- and femtosecond two-photon excitation: signal and photodamage. Biophys J 77:2226-2236.

Kruk PJ, Korn H, Faber DS (1997) The effects of geometrical parameters on synaptic transmission: a Monte Carlo simulation study. Biophys J 73:2874-2890.

Lei S, Pelkey KA, Topolnik L, Congar P, Lacaille JC, McBain CJ (2003) Depolarization-induced long-term depression at hippocampal mossy fiber-CA3 pyramidal neuron synapses. J Neurosci 23:9786-9795.

Lim R, Alvarez FJ, Walmsley B (1999) Quantal size is correlated with receptor cluster area at glycinergic synapses in the rat brainstem. J Physiol (Lond) 516:505-512.

Linden DJ (2001) The expression of cerebellar LTD in culture is not associated with changes in AMPA-receptor kinetics, agonist affinity, or unitary conductance. Proc Natl Acad Sci USA 98:14066-14071.

Litschig S, Gasparini F, Rueegg D, Stoehr N, Flor PJ, Vranesic I, Prézeau L, Pin JP, Thomsen C, Kuhn R (1999) CPCCOEt, a noncompetitive metabotropic glutamate receptor 1 antagonist, inhibits receptor signaling without affecting glutamate binding. Mol Pharmacol 55:453-461.

Liu G (2003) Presynaptic control of quantal size: kinetic mechanisms and implications for synaptic transmission and plasticity. Curr Opin Neurobiol 13:324-331.

Liu G, Choi S, Tsien RW (1999) Variability of neurotransmitter concentration and nonsaturation of postsynaptic AMPA receptors at synapses in hippocampal cultures and slices. Neuron 22:395-409.

Lübke J (1993) Photoconversion of diaminobenzidine with different fluorescent neuronal markers into a light and electron microscopic dense reaction product. Microsc Res Tech 24:2-14.

Matsuzaki M, Ellis-Davies GC, Nemoto T, Miyashita Y, Iino M, Kasai H (2001) Dendritic spine geometry is critical for AMPA receptor expression in hippocampal CAl pyramidal neurons. Nat Neurosci 4:1086-1092.

Matsuzaki M, Honkura N, Ellis-Davies GC, Kasai H (2004) Structural basis of long-term potentiation in single dendritic spines. Nature 429:761-766.

Momiyama A, Silver RA, Hausser M, Notomi T, Wu Y, Shigemoto R, Cull-
Candy SG (2003) The density of AMPA receptors activated by a transmitter quantum at the climbing fibre-Purkinje cell synapse in immature rats. J Physiol (Lond) 549:75-92.

Nusser Z (1999) A new approach to estimate the number, density and variability of receptors at central synapses. Eur J Neurosci 11:745-752.

Nusser Z, Cull-Candy S, Farrant M (1997) Differences in synaptic GABA(A) receptor number underlie variation in GABA mini amplitude. Neuron 19:697-709.

Nusser Z, Lujan R, Laube G, Roberts JD, Molnar E, Somogyi P (1998) Cell type and pathway dependence of synaptic AMPA receptor number and variability in the hippocampus. Neuron 21:545-559.

Nusser Z, Naylor D, Mody I (2001) Synapse-specific contribution of the variation of transmitter concentration to the decay of inhibitory postsynaptic currents. Biophys J 80:1251-1261.

Otis TS, Wu YC, Trussell LO (1996) Delayed clearance of transmitter and the role of glutamate transporters at synapses with multiple release sites. J Neurosci 16:1634-1644.

Partin KM, Fleck MW, Mayer ML (1996) AMPA receptor flip/flop mutants affecting deactivation, desensitization, and modulation by cyclothiazide, aniracetam, and thiocyanate. J Neurosci 16:6634-6647.

Pereda A, O’Brien J, Nagy JI, Bukauskas F, Davidson KG, Kamasawa N, Yasumura T, Rash JE (2003) Connexin35 mediates electrical transmission at mixed synapses on Mauthner cells. J Neurosci 23:7489-7503.

Rusakov DA, Kullmann DM (1998) Extrasynaptic glutamate diffusion in the hippocampus: ultrastructural constraints, uptake, and receptor activation. J Neurosci 18:3158-3170.

Sigworth FJ (1980) The variance of sodium current fluctuations at the node of Ranvier. J Physiol (Lond) 307:97-129.

Silver RA (2003) Estimation of nonuniform quantal parameters with multiple-probability fluctuation analysis: theory, application and limitations. J Neurosci Methods 130:127-141.

Silver RA, Cull-Candy SG, Takahashi T (1996) Non-NMDA glutamate receptor occupancy and open probability at a rat cerebellar synapse with single and multiple release sites. J Physiol (Lond) 494:231-250.

Smith MA, Ellis-Davies GC, Magee JC (2003) Mechanism of the distancedependent scaling of Schaffer collateral synapses in rat CA1 pyramidal neurons. J Physiol (Lond) 548:245-258.

Takumi Y, Ramírez-León V, Laake P, Rinvik E, Ottersen OP (1999) Different modes of expression of AMPA and NMDA receptors in hippocampal synapses. Nat Neurosci 2:618-624.

Wadiche JI, Jahr CE (2001) Multivesicular release at climbing fiberPurkinje cell synapses. Neuron 32:301-313.

Xu C, Zipfel W, Shear JB, Williams RM, Webb WW (1996) Multiphoton fluorescence excitation: new spectral windows for biological nonlinear microscopy. Proc Natl Acad Sci USA 93:10763-10768. 